\title{
The Effect of Nanoencapsulated Phaleria macrocarpa Fruits Extract in Drinking Water on Jejunal Histomorphology of Broiler Chickens
}

\author{
N. Ningsih ${ }^{\mathrm{a}, \mathrm{b}}$, B. Ariyadic, N. D. Dono ${ }^{\mathrm{a}}$, Supadmo ${ }^{\mathrm{a}}$, \& Zuprizal ${ }^{\mathrm{a}, *}$ \\ aDepartment of Animal Feed Science, Faculty of Animal Science, Universitas Gadjah Mada \\ ${ }^{\mathrm{b}}$ Politeknik Negeri Jember \\ Jalan Mastrip PO BOX 164 Jember, Jawa Timur 68101, Indonesia \\ cDepartment of Animal Production, Faculty of Animal Science, Universitas Gadjah Mada \\ Jalan Fauna No. 3 Bulaksumur, Yogyakarta 55281, Indonesia \\ *Corresponding author: zuprizal@ugm.ac.id \\ (Received 30-11-2018; Revised 31-12-2018; Accepted 07-02-2019)
}

\begin{abstract}
The purpose of this study was to investigate the characteristics of nanoencapsulated Phaleria macrocarpa fruits extract (NEPM) in drinking water and its effect on microbial population and histomorphology in the jejunal wall of broiler chickens. A total number of 200 male broiler chicks were distributed into 5 treatments with 4 replicates ( 10 birds in each replicate). The experimental treatments were control diet (T0; negative control), diet with tetracycline (T1; positive control), diet with $2.5 \%$ of Phaleria macrocarpa fruits extract (T2), diet with 2.5\% NEPM (T3), and diet with $5.0 \%$ NEPM (T4). The diet was yellow corn and soybean meal that contains $20.44 \% \mathrm{CP}, 2917.47 \mathrm{kcal} / \mathrm{kg} \mathrm{ME}$, $0.84 \% \mathrm{Ca}$, and $0.51 \%$ Pav. Variables evaluated were characteristics of NEPM, growth performance, intestinal microbial population (lactic acid bacteria (LAB) and Salmonella sp.), and intestinal histomorphology (villus height, crypt depth, and villus height to crypt depth ratio (VH : CD)). Data were analyzed using ANOVA in a completely randomized design. Orthogonal contrast test were used to separate mean of data when p-value differ significantly. Results showed that the size of NEPM was $778 \mathrm{~nm}$ with spherical shape and positive charges with the zeta potentials of $+26.5 \mathrm{mV}$. Supplementing $5 \%$ of NEPM did not affect broiler growth performance, Salmonella sp. or crypt depth, but increased ( $<<0.05) \mathrm{LAB}$, villi height, and VH:CD. It can be concluded that $5.0 \%$ of NEPM in the drinking water had positive effect on the jejunal histomorphology and increased population of LAB while Salmonella sp. was not detected on all treatments.
\end{abstract}

Keywords: broiler chicken; jejunal bacteria; jejunal morphology; nanoencapsulation; Phaleria macrocarpa fruits

\section{INTRODUCTION}

The use of antibiotics as feed additive and growth promoter (AGP's) for animal has been prohibited by the Indonesian government regulated by the Ministry of Agriculture, Republic of Indonesia (PERMENTAN) in the number of 14/PERMENTAN/PK.350/5/2017. Antibiotic is an antimicrobial agent functioned to kill microorganism, primarily pathogenic microbes in the intestine. Antibiotic was fabricated from fungi or bacteria, and has activity to enhance immune system, optimize digestive system, and improve growth performance of broiler chicken, but the specification mode of action remains unclear (Mehdi et al., 2018). Intestinal microbiota plays an important role to promote healthy intestinal community, immunological, and improve nutrient digestion and absorption, thus improve animal growth performance. On the other hands, uncontrolled usage of antibiotics leads to accumulation of undesirable residues in the animal tissues and their products, and cause foodborne disease to human. Therefore, researcher has been intensively investigated natural substances for their potencies as AGP's replacer in the diet. Phytogenic feed additive becomes familiar due to its beneficial effect on broiler performance attributed to their bioactive compounds (Wati et al., 2015).

Phytobiotic, herbs or plants extract, is supplemented in animal feed to improve poultry production. There are two major mechanisms of phytobiotic in increasing animal production as antimicrobial agents and increasing nutrient absorption (Fallah et al., 2013). One of the Indonesian plants that have potency to be used as phytobiotics is Phaleria macrocarpa. This plant is well known as a medicinal plant and contains diverse bioactive compounds, such as phenolic, benzhophenone, terpenes, and alkaloid (Alara \& Olalere, 2016). These compounds have antimicrobial activities with different mode of actions. The low efficacy of $P$. macrocarpa diets-supplementation is caused by the low solubility, fast degradable, low bioavailability, and thermolabile with the temperature of animal digestion organs. Nanoencapsulation technology is one of alternative solutions to overcome these problems. 
Encapsulating the fruit extract beneficially conserves the bioactive substances in nanometer size and refers to bioactive packing. Nanoencapsulation has several benefits, such as preserve bioactive compounds of phytobiotic, increase the affectivity of bioactive distribution in the gut, increase the physical stability of the bioactive substances, and protect them from degradation in the gut (Donsì et al., 2011). Nanoencapsulation can be made with ionic gelation method using chitosan and sodium tripolyphosphate (STPP). Ionic gelation method is based on different charges between the negative charges STPP and positive charges of chitosan (Sundari et al., 2014). Chitosan is obtained from deacetylation of the naturally polysaccharide chitin, one of the most abundant biopolymers in nature. Chitosan is known as a natural, biodegradable, biocompatible, and bioadhesive polymer. STPP is polyanion that used as cross-link agent. The interaction of chitosan with STPP leads to the formation of biocompatible cross-linked chitosan nanoparticles, which can efficiently deliver bioactive of phytobiotics as antibacterial agent in broiler intestine.

Few investigations have been reported about $P$. macrocarpa as phytobiotics to replace antibiotics, whereas $P$. macrocarpa had wide variety of useful pharmacological activities, such as anti-microbial, anti-fungal, antioxidant activity, and its non-toxic activity (Alara et al., 2016). Moreover, combination of $P$. macrocarpa with nanoencapsulation technology as a phytobiotic for broiler chicken had never been studied before. The purpose of this study was to investigate the characteristics of nano-encapsulated $P$. macrocarpa fruits extract, and its effect of nanoencapsulation in drinking water administration on broiler growth performance, intestinal microbial population, and micro-morphology of jejunum cell wall of broilers chickens.

\section{MATERIALS AND METHODS}

\section{Animal, Diets, and Experimental Design}

The study was conducted at the Faculty of Animal Science, Universitas Gadjah Mada, Yogyakarta,
Indonesia. A total number of 200 male eight days old New Lohmann MB 202 broiler chickens were distributed into five treatments and four replicates with 10 birds in each replicate pen. Each pen was equipped with a feeder and a water trough. The basal diets were formulated to meet the nutrition recommendations of broiler chickens from NRC (1994), based on yellow corn and soybean meal, which contained $20.44 \%$ crude protein $(\mathrm{CP}), 2917.47 \mathrm{kcal} / \mathrm{kg}$ metabolizable energy (ME), $0.84 \%$ Calcium (Ca), and $0.51 \%$ available Phosphorus (Pav). Chemical compositions of the diets were analyzed according to AOAC (2005). Formulation and chemical compositions for the experimental diets are shown in Table 1 . The diets and drinking water were supplied ad libitum from days 8 to 35 (Reyes et al., 2018). The initial growth (0-7 days) is a critical phase for intestinal development, at the moment the segments of the gastrointestinal tract and digestive organs increase in size and weight more rapidly in relation to body weight than the other organs and tissues. Therefore, in this age, all of broilers chickens were given the same treatment in order to have the same well-functioning of gastrointestinal tract before giving the treatments. The experimental treatments were consisted of basal diet (T0; negative control), basal diet with antibiotic tetracycline (T1; positive control), and basal diet with $2.5 \%$ of $P$. macrocarpa fruits extract (T2), 2.5\% nanoencapsulation of P. macrocarpa (NEPM) (T3), and 5.0\% NEPM (T4).

\section{Nanoencapsulation Procedure}

The nanoencapsulation of $P$. macrocarpa fruits extract was formulated by ionic gelation method using $2 \%$ of $P$. macrocarpa fruits extract, $0.625 \%$ chitosan, $0.75 \%$ sodium-tripolyphosphate (STPP) (w/v), and consisted of 0.5: 1.0: 0.02 of extract, chitosan, and STPP, respectively. Initially, the fruits were extracted by macerating $P$. macrocarpa meal with $96 \%$ ethanol $(1: 100 \mathrm{w} / \mathrm{v})$ in 3 days. The filtrate was then filtered using Whatman paper number 1 and was evaporated using waterbath at a temperature of $60^{\circ} \mathrm{C}$ to remove ethanol.

Table 1 . Ingredients and chemical composition of the basal diet

\begin{tabular}{lcccccccc}
\hline \multirow{2}{*}{\multicolumn{1}{c}{ Ingredients }} & \multirow{2}{*}{ Proportion $(\%)$} & \multicolumn{7}{c}{ Chemical compositions } \\
\cline { 3 - 9 } & & $\mathrm{CP}(\%)$ & $\mathrm{ME}(\mathrm{kcal} / \mathrm{kg})$ & $\mathrm{Ca}(\%)$ & Pav $(\%)$ & Lys $(\%)$ & Met $(\%)$ & Thr $(\%)$ \\
\hline Yellow corn & 55.70 & 4.96 & 1881.10 & 0.01 & 0.13 & 0.16 & 0.10 & 0.20 \\
Soybean meal & 31.00 & 13.83 & 686.96 & 0.09 & 0.19 & 0.79 & 0.16 & 0.49 \\
Meat bone meal & 1.50 & 0.70 & 28.85 & 0.14 & 0.07 & 0.04 & 0.01 & 0.02 \\
Rice brand & 8.00 & 0.96 & 230.96 & 0.00 & 0.10 & 0.04 & 0.02 & 0.03 \\
Palm oil & 1.50 & 0.00 & 132.60 & 0.00 & 0.0 & 0.00 & 0.00 & 0.00 \\
Vitamin premix & 0.30 & 0.00 & 0.00 & 0.49 & 0.02 & 0.00 & 0.00 & 0.00 \\
L-lysine $\mathrm{HCl}(98 \%)$ & 0.10 & 0.09 & 3.61 & 0.00 & 0.00 & 0.07 & 0.00 & 0.00 \\
DL-methionine (99\%) & 0.20 & 0.12 & 7.22 & 0.00 & 0.00 & 0.00 & 0.20 & 0.00 \\
CaCO & 1.50 & 0.00 & 0.00 & 0.10 & 0.00 & 0.00 & 0.00 & 0.00 \\
NaCl & 0.20 & 0.00 & 0.00 & 0.00 & 0.00 & 0.00 & 0.00 & 0.00 \\
Total & 100.00 & 20.66 & 2971.30 & 0.83 & 0.51 & 1.10 & 0.48 & 0.74 \\
\hline
\end{tabular}

Note: CP: Crude protein; ME: Metabolizable Energy, Ca: Calcium; Pav: Available Phosphor; Lys: Lysine; Met: Methionine; Thr: Threonin *Vitamin premix (Masamix-Bro) chemical composition was Vit. A: 12,500,000 IU; Vit D3: 2,500,000 IU; VitE: 10000 mg; VitK3: 2000 mg; Vit.B1: 2000 mg; Vit. B2: 4000 mg; Vit. B6: 1000 mg; Vit. B12: 12000 mcg; Vit.C: 40000 mg; Niacin: 40000 mg; Biotin: 200 mg. 
Nanoencapsulation were produced by dissolving $2 \%$ of aqueous $P$. macrocarpa fruits extract with $0.625 \%$ of chitosan which has dissolved previously with acetic acids. Both $2 \%$ extract and $0.625 \%$ chitosan ware mixed using magnetic stirrer (C-MAG HS 7, IKA, Selangor, Malaysia) for 30 minutes, and then added with $0.75 \%$ aqueous STPP and mixed using stirrer for 30 minutes (Sundari et al., 2014).

\section{Analysis of Characterization Nanoencapsulation}

Particle size and potential zeta. Particle size and potential zeta of NEPM were determined by a Dynamic Light Scattering (DLS) method. Five mL of NEPM was analyzed for particle size with Particle Size Analyzer (PSA) (Horiba Scientiific SZ - 100, Horiba, Kyoto, Japan). Evaluation was done using scattering angle of $90^{\circ} \mathrm{C}$ with temperature holder of $24.8^{\circ} \mathrm{C}$ according to Liang et al. (2017).

Nano morphology. Morphological structure of NEPM was evaluated using Transmission Electron Microscopy (TEM) (JEOL JEM 1400 Plus, Jeol, Peabody, USA). The samples were prepared by dropping solutions into Copper grids coated with carbon using the auto carbon coated for 5 minutes, prior the samples drying. The samples were stayed in the copper network for 2-3 min. The samples were then immersed in $2 \%$ phosphotungstic acid stain and stained for 2-3 min. After natural drying, the samples were placed under TEM for observation according to Liang et al. (2017).

\section{Broiler Growth Performance and Carcass Analysis}

Feed consumption, feed conversion ratio (FCR), and water consumption were recorded daily. Body weight gain of broiler chicken was weighted weekly. At days 35, a chicken from each different replicates was randomly selected to slaughter according to Islamic law to measure carcass percentage.

\section{Determinations of Microbial Populations}

At the end of the 35 days rearing period, one bird per group with body weight closed to the median of each group was randomly selected for sample collection. Jejunal ingesta from the 4 birds were separately placed on agar plates for further analysis. These samples were used to enumerate the number of lactic acid bacteria and Salmonella sp. in the small intestine. Lactic acid bacteria (LAB) was cultured using de Man, Rogosa, and Sharpe agar or MRSA (Oxoid, Basingstoke, Hampshire, UK), while Salmonella sp. was cultured using Salmonella shigella Agar or SS (Oxoid, Basingstoke, Hampshire, UK).

Digesta samples with approximately $1 \mathrm{~g}$ were squeezed from jejunum into $9 \mathrm{~mL}$ peptone water solution. The solution was mixed with vortex. The suspension was prepared from dilutions $10^{-1}$ and serial dilutions were done $\left(10^{-2}, 10^{-3}, 10^{-4}, 10^{-5}, 10^{-6}, 10^{-7}\right.$, $10^{-8}$, and $\left.10^{-9}\right)$. One $\mathrm{mL}$ solution was removed from three dilutions and poured into petri dishes containing the medium. The total number of LAB and Salmonella sp. colony were counted after incubation in an $37^{\circ} \mathrm{C}$ anaerobic chamber for 48 hours. Enumeration of total bacteria was carried out manually using total plate count (TPC) method (Halimatunnisroh et al., 2017).

\section{Morphology of Jejunum}

At days 35, a chicken from each different replicates was slaughtered according to Islamic law. The jejunum sample was separated from the end duodenal loop up to $1 \mathrm{~cm}$ proximal to the Meckel's diverticulum. Sections of approximately $6 \mathrm{~cm}$ were taken from the mid-jejunum, gently flushed with physiologic $\mathrm{NaCl}$, and cut into 3 equal pieces. The jejunal sections were immediately fixed into $10 \%$ formalin solution for further analyses. Histological examination was prepared initially by transferring the jejunal samples with a series of alcohol with increasing concentration (70\%, 80\%, 90\%, and $100 \%$ ), xylol solution, and followed by embedding in paraffin wax. Transverse and longitudinal sections with $4 \mu \mathrm{m}$ in thickness were prepared using microtome, stained with Hematoxyline-Eosin, and examined under the electron transmission microscope (Optilab Advance, Miconos, Yogyakarta, Indonesia). The villus height (VH) was measured from the tip of the villus to the villuscrypt junction, while crypt depth (CD) was defined as the depth of the invagination between two villi (Ariyadi et al., 2014).

\section{Statistical Analysis}

Characteristic of nanoencapsulated $P$. macrocarpa fruits extract was reported descriptively for particle size, zeta potential, and morphology. Data of growth performance, microbial population, and morphology of jejunal intestine were expressed as mean \pm STdev, and the number of jejunal microbes was presented in colony forming unit (CFU/g) of digesta and expressed in Log 10. The data were statistically analyzed by one-way ANOVA with completely randomized design, using Statistical Package for Social Science or SPSS (SPSS $\mathrm{GmbH}$, Munich, Germany). Orthogonal contrast test was used to separate data with significance difference. All indication of significance was based on a probability of less than $5 \%$.

\section{RESULTS}

\section{Characteristic of Nano-encapsulation}

Nanoencapsulation of $P$. macrocarpa fruits extract (NEPM) was successfully obtained by ionic gelation method with combination of positive charges from chitosan and negative charges from STPP. The NEPM has $\mathrm{pH} 3.31$ and visible clear solution. Using DLS measurements, NEPM showed particle size distribution of $778 \mathrm{~nm}$. Zeta potential of NEPM was positive charges with value of $+26.5 \mathrm{mV}$. NEPM TEM image displayed a homogeneous distribution and stable formulation with spherical shape and coated with transparent layer from ionic gelation between chitosan and STPP. The image of NEPM morphology is showed in Figure 1. 


\section{Growth Performance of Broiler Chicken}

The use of different levels of nanoencapsulation of P. macrocarpa fruits extract did not significantly affect feed consumption, feed conversion ratio, water consumption, and carcass percentage. The data are presented in Table 2.

\section{Microbial Population of Jejunal Intestine of Broilers Chickens}

The results for bacterial populations in the jejunal intestine are presented in Table 3. There was a significant effect $(\mathrm{p}<0.05)$ of NEPM supplementation on the population of Lactic acid bacteria (LAB). Orthogonal contrast test of LAB population was showed in Table 4. Orthogonal contrast examination showed that the use of tetracycline and supplementation of nanoparticle of $P$. macrocarpa fruit extract increased $(\mathrm{p}<0.05)$ the population of LAB in the gut of broiler chickens. The results indicated that there was no significant difference between the number of LAB in the gut of broiler chickens fed diets supplemented with nonoencapsulated and nano- capsulated extracts of $P$. macrocarpa. The population of Salmonella sp. was not detected in any treatments.

\section{Morphology of Jejunal Intestine of Broilers Chickens}

The effects of NEPM supplementation in the drinking water on histomorphology of the jejunal mucosa layer in broiler chickens are summarized in Table 5. The results showed that NEPM increased the villus height and villus height to crypt depth ratio $(p<0.01)$, but did not affect crypt depth. Orthogonal contrast data of villus height are presented in Table 6 and VH:CD ratio are presented in Table 7 . The data showed that antibiotic and NEPM supplementations increased villus height $(\mathrm{p}<0.05)$ and $\mathrm{VH}: \mathrm{CD}$ ratio $(\mathrm{p}<0.01)$, compared with negative control diet.

\section{DISCUSSION}

\section{Characteristics of Nanoencapsulation}

The particle size of nanoencapsulation of $P$. macrocarpa was $773 \mathrm{~nm}$ and these results appropriate with

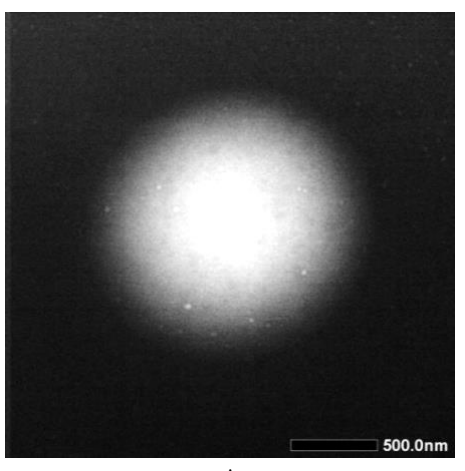

A

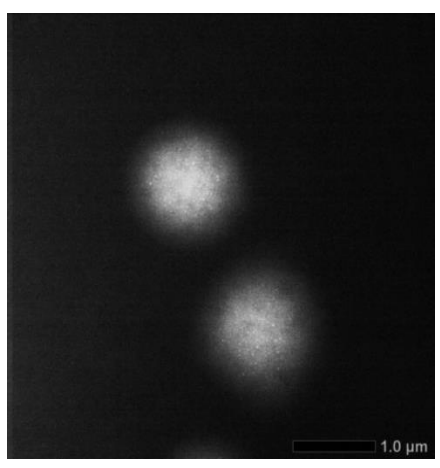

B

Figure 1. Morphology of nano-encapsulation in $500 \mathrm{~nm}$ scale (A) and in $1000 \mathrm{~nm}$ scale (B)

Table 2. The performance (mean \pm STdev) of broiler chickens fed with different percentages of nano-encapsulation of Phaleria macrocarpa fruits extract (NEPM)

\begin{tabular}{lrrrrrr}
\hline \multirow{2}{*}{ Variables } & \multicolumn{5}{c}{ Treatments } & \multicolumn{1}{c}{ T-value } \\
\cline { 2 - 6 } & \multicolumn{1}{c}{ T0 } & \multicolumn{1}{c}{ T1 } & \multicolumn{1}{c}{ T2 } & T4 & T3 \\
\hline Feed consumption (g/bird/35 days) & $2624.56 \pm 72.73$ & $2711.98 \pm 44.79$ & $2711.41 \pm 42.47$ & $2668.28 \pm 34.23$ & $2729.95 \pm 68.26$ & 0.092 \\
Weight gain (g/bird/35 days) & $1596.56 \pm 97.58$ & $1618.64 \pm 84.48$ & $1656.18 \pm 42.73$ & $1635.58 \pm 27.33$ & $1674.75 \pm 30.30$ & 0.471 \\
Feed conversion ratio & $1.61 \pm 0.07$ & $1.64 \pm 0.06$ & $1.60 \pm 0.02$ & $1.61 \pm 0.02$ & $1.61 \pm 0.02$ & 0.813 \\
Carcass (\%) & $66.53 \pm 2.95$ & $67.60 \pm 4.31$ & $65.61 \pm 2.85$ & $66.47 \pm 5.32$ & $68.01 \pm 0.15$ & 0.881 \\
Water consumptiom & $7.91 \pm 0.56$ & $7.70 \pm 0.32$ & $7.54 \pm 0.25$ & $7.20 \pm 0.68$ & $7.52 \pm 0.11$ & 0.272 \\
(L/bird/35 day) & & & & & & \\
\hline
\end{tabular}

Note: T0: negative control without feed additive, T1: Positive control with antibiotic tetracycline, T2: $2.5 \%$ of Phaleria Macrocarpa fruits extract nonencapsulated, T3: 2.5\% NEPM, T4: 5\% NEPM.

Table 3. Microbial population of jenunal intestine (mean \pm STdev) of broiler chickens fed with different percentage of nanoencapsulation of Phaleria macrocarpa fruits extract (NEPM)

\begin{tabular}{|c|c|c|c|c|c|c|}
\hline \multirow{2}{*}{ Species } & \multicolumn{5}{|c|}{ Treatments } & \multirow{2}{*}{$\mathrm{p}$-value } \\
\hline & T0 & T1 & $\mathrm{T} 2$ & T3 & $\mathrm{T} 4$ & \\
\hline BAL (Log cfu/g) & $6.81 \pm 0.64$ & $7.15 \pm 0.20$ & $8.64 \pm 0.25$ & $8.80 \pm 0.08$ & $9.21 \pm 0.45$ & $<0.01$ \\
\hline Salmonella sp. & No growth & No growth & No growth & No growth & No growth & - \\
\hline
\end{tabular}

Note: T0: negative control without feed additive, T1: Positive control with antibiotic tetracycline, T2: $2.5 \%$ of Phaleria Macrocarpa fruits extract nonencapsulated, T3: 2.5\% NEPM, T4: 5\% NEPM. 
nanoparticle requirement, that should less than $1 \mathrm{~mm}$. The height of nanoparticle size from this study attributed to the height of percentage between chitosan and STPP. The height of concentration between chitosan and STPP led to the increased particle size caused by agglomeration of chitosan. Several factors that influence the particles size of nanoparticles are the molecular weight of chitosan, the concentration of STPP, the

Table 4. Orthogonal contrast of lactic acid bacteria population in jenunal intestine of broiler chickens fed with different percentages of nano-encapsulation of Phaleria macrocarpa fruits extract (NEPM)

\begin{tabular}{lc}
\hline \multicolumn{1}{c}{ Treatments } & LAB (Log cfu/g) \\
\hline T0 & $6.81 \pm 0.64$ \\
T1 & $7.15 \pm 0.20$ \\
T2 & $8.64 \pm 0.25$ \\
T3 & $8.80 \pm 0.08$ \\
T4 & $9.21 \pm 0.45$ \\
p-values for main effect of diets & $<0.01$ \\
p-values for contrast & \\
T0 vs T1, T2, T3, T4 & $<0.01$ \\
T1 vs T2, T3, T4 & $<0.01$ \\
T2 vs T3, T4 & 0.143 \\
\hline
\end{tabular}

Note: LAB: Lactic acid bacteria, T0: negative control without feed additive, T1: Positive control with antibiotic tetracycline, T2: $2.5 \%$ of Phaleria macrocarpa fruits extract non-encapsulated, T3: 2.5\% NEPM, T4: 5.0\% NEPM weight ratio of TPP to chitosan, reaction temperature, and $\mathrm{pH}$ (Ningsih et al., 2017; Lee at al., 2016).

The TEM image revealed that NEPM had spherical shape. The present research is in agreement with Alves et al. (2016) who previously reported spherical appearance of nanoencapsulation of gallic acid. In addition, Blaiszik et al. (2008) also stated that nanoencapsulation with self-healing material produced spherical shape, closed to monodisperse in capsule diameter, and smooth non-porous shell wall.

Chitosan-tripolyphosphate nanoparticles mixed with each other led spontaneously formed compact complexes with an overall positive surface charge. Ionization process from amino group of chitosan stimulate to positive zeta potential. Positive zeta potential might ease nanoparticle to interact with mucus that has negative charges, and makes the drug delivery more effective, thus improve the availability of the drug in the tissue. Positive zeta potential showed a stronger electrostatic interaction with mucus or with mucosa surface. Zeta potential of $>25 \mathrm{mV}$ showed the stable formulation and had high affinity on the cell membrane (Motiei et al., 2017; Honary \& Zahir, 2012). In the present experiment, positive zeta potential of the NEPM was $+26,5 \mathrm{mV}$, indicated a stable formulation.

\section{Broiler Growth Performance}

There was no significant difference in growth performance of broiler chicken. Our finding agreed

Table 5. Morphology of jejunal intestine (mean \pm STdev) of broiler chickens fed with different percentages of nano-encapsulation of Phaleria macrocarpa fruits extract (NEPM)

\begin{tabular}{|c|c|c|c|c|c|c|}
\hline \multirow{2}{*}{ Item } & \multicolumn{5}{|c|}{ Treatments } & \multirow{2}{*}{$\mathrm{p}$-value } \\
\hline & T0 & T1 & $\mathrm{T} 2$ & T3 & $\mathrm{T} 4$ & \\
\hline Villus height $(\mu \mathrm{m})$ & $550.04 \pm 60.10$ & $607.99 \pm 126.77$ & $782.82 \pm 104.47$ & $1173.77 \pm 179.65$ & $1428.90 \pm 176.46$ & $<0.01$ \\
\hline Crypt depth $(\mu m)$ & $121.52 \pm 9.07$ & $98.70 \pm 27.01$ & $128.09 \pm 10.41$ & $102.60 \pm 31.87$ & $123.71 \pm 18.50$ & 0.24 \\
\hline $\mathrm{V}: \mathrm{C}$ ratio & $4.52 \pm 0.19$ & $6.25 \pm$ & $6.10 \pm$ & $12.45 \pm$ & $11.66 \pm$ & $<0.01$ \\
\hline
\end{tabular}

Note: V:C Ratio= Villus height : Crypts depth ratio. T0: negative control without feed additive, T1: Positive control with antibiotic tetracycline, T2: $2.5 \%$ of Phaleria Macrocarpa fruits extract non-encapsulated, T3: 2.5\% NEPM, T4: 5\% NEPM.

Table 6. Orthogonal contrast of villus height jejunal intestine of broiler chickens given nano-encapsulation of Phaleria macrocarpa fruits extract (NEPM)

\begin{tabular}{lc}
\hline \multicolumn{1}{c}{ Treatments } & Villus height $(\mu \mathrm{m})$ \\
\hline T0 & $550.04 \pm 60.10$ \\
T1 & $607.99 \pm 126.77$ \\
T2 & $782.82 \pm 104.47$ \\
T3 & $1173.77 \pm 179.65$ \\
T4 & $1428.90 \pm 176.46$ \\
p-values for main effect of diets & $<0.01$ \\
p-values for contrast & \\
T0 vs T1, T2, T3, T4 & $<0.01$ \\
T1 vs T2, T3, T4 & $<0.01$ \\
T2 vs T3, T4 & 0.054 \\
\hline
\end{tabular}

Note: T0: negative control without feed additive, T1: Positive control with antibiotic tetracycline, T2: $2.5 \%$ of Phaleria macrocarpa fruits extract non-encapsulated, T3: 2.5\% NEPM, T4: 5.0\% NEPM
Table 7. Orthogonal contrast of villus height to crypt depth ratio jejunal intestine of broiler chickens given nano-encapsulation of Phaleria macrocarpa fruits extract (NEPM)

\begin{tabular}{lc}
\hline \multicolumn{1}{c}{ Treatments } & $\begin{array}{c}\text { Villus height to crypt } \\
\text { depth ratio }\end{array}$ \\
\hline T0 & $4.52 \pm 0.19$ \\
T1 & $6.25 \pm 0.56$ \\
T2 & $6.10 \pm 0.44$ \\
T3 & $12.45 \pm 4.36$ \\
T4 & $11.66 \pm 1.44$ \\
p-values for main effect of diets & $<0.01$ \\
p-values for contrast & \\
T0 vs T1, T2, T3, T4 & 0.004 \\
T1 vs T2, T3, T4 & 0.166 \\
T2 vs T3, T4 & 0.053 \\
\hline
\end{tabular}

Note: T0: negative control without feed additive, T1: Positive control with antibiotic tetracycline, T2: $2.5 \%$ of Phaleria macrocarpa fruits extract non-encapsulated, T3: 2.5\% NEPM, T4: 5.0\% NEPM 
with research by Sundari et al. (2014) who observed that feed consumption, feed conversion, and carcass weight was not affected by nanoencapsulation of turmeric extract. The possible reason may be attributed to the characteristic of nanoencapsulation of $P$. macrocarpa fruits extract. Bunglavan et al. (2014) found that several factors that influence the activity of nano-encapsulation in the digestive tract are physicochemical characteristics such as solubility charge and size. Increasing the particle size of nanoencapsulation up to $778 \mathrm{~nm}$ has an impact on particle distribution on the intestinal mucosa of broiler chicken, the distribution more slowly and less effective than small particle size. Parera et al. (2015) and Katouzian \& Jafari (2016) reported that nanoparticle with $<500 \mathrm{~nm}$ shows the best rapidity flow in the intestinal mucosa. Higher particle size means the compound will be more slowly distributed and release $(50>200>$ 500). There are very limited findings about phytobiotic $P$. macrocarpa to support this result. Therefore, further research is needed to investigate the effects of nanoencapsulation of $P$. macrocarpa with better characteristics.

\section{Microbial Populations}

Increasing LAB populations due to NEPM supplementation was similar with that reported by Natsir et al. (2013) who found that supplementation of phytobiotic, encapsulated or non-encapsulated, increased the number of LAB in intestine of Lohmann broiler chickens. Similarly, Ürüşan \& Bölükbaşı (2017) showed that supplementation of non-encapsulated turmeric powder increased the colony of BAL in the gut of Ross 308 commercial line broiler chickens.

P. macrocarpa contains variety of bioactive compounds such us phenolic and garlic acids that can speed up the growth of LAB and control the growth of pathogenic bacteria. This action might be closely related to the reduction of intestinal $\mathrm{pH}$. Organic acids are able to kill pathogenic bacteria through the interruption of the lipid membrane formation on the bacterial cell and increase the plasma acidity. This condition promote bacteria that intolerant with the low $\mathrm{pH}$ cannot adapt with the more acid environment (Fascina et al., 2012). Alara \& Olalere (2016) reported that phenolic compounds of eight berries inhibited the growth of selected gram-negative bacteria and were not active against gram positive LAB. Increasing $\mathrm{LAB}$ population in broiler chicken indicated the better gastrointestinal conditions, because LAB potentially improved nutrient digestibility especially with cellulose content (Herdian et al., 2018).

In the current study, Salmonella sp. was not found in all treatments. It was similar with Choiri et al. (2017) that reported no population of Salmonella sp. on the intestinal mucose of laying hens that received nanoencapsulated noni extract in drinking water. Result in this study might be related with the used of coarse litter. The coarse wood components in litter may play a significant role in reducing the colonization and population of Salmonella sp by providing antimicrobial agents against exclusion microorganisms or by giving stimulation of the gizzard and proventriculus (Santos et al., 2008).

\section{Morphology of Jejunal Intestine}

The effects of NEPM supplementation in drinking water on the jejunal morphology of broiler chicken contributed in improving villus height and VH:CD ratio. Both antibiotics and phytobiotic have the ability to stop the growth and even kill pathogenic microbes, reduce the number of toxins in the intestine, lower the secretion of the intestinal barrier, and trigger the growth of villus on the wall of the intestine (Awad et al., 2012). Villus height and crypt depth exhibit the intestinal health, as well as nutrient digestion and absorption. Longer villi and shorter crypt leads to the higher performance that associated with the absence of microbial toxins. A study by Rahman et al. (2017) showed that supplementation of onion (Allium cepa L.) extract/powder modified the gut microbiota, increased villus health, increased nutrient digestibility and absorption. Iriyanti et al. (2018) also reported that the small intestine functions as feed digestion and nutrients absorptions that were influenced by the epithelial intestine and the conditions and amount of microvilli.

Nanoencapsulated trial showed higher $\mathrm{CH}: \mathrm{CD}$ ratio than nonencapsulated group as this results may be due to nanoencapsulated can defend the bioactive compounds of $P$. macrocarpa than the bioactive can efficiently distribute and release in animal gut as antibacterial activity. Donsi et al. (2011) reported that nanocapsules of essential oils were able to delay the microbial growth or completely inactivate the microorganisms and can increase the growth of intestinal morphology. On the other hand, supplementation of NEPM was no significant effect on crypt depth. This result similarly with Chori et al. (2017) reporting that no significant effect on crypt depth of laying hens with supplementation of nanoencapsulation of noni extract.

\section{CONCLUSION}

In conclusion, the present study discovered that NEPM could be beneficially used as an alternative for antibiotics in the diets of broiler chickens. NEPM can significantly enhance the population of the lactic acid bacteria, the growth and proliferation of absorptive cell on the jejunum of broiler chickens, and the population of Salmonella sp was not found in all treatments.

\section{CONFLICT OF INTEREST}

The researchers state that no conflict of interest with any financial, personal, or other relationships with other people or organization related to the material discussed in the manuscript.

\section{ACKNOWLEDGEMENT}

This research was fully supported by Indonesia Endowment Fund for Education (LPDP), Ministry of Finance, and Republic of Indonesia by Master Thesis Scholarship Allowance (contract number PRJ-1151/ LPDP.3/2016). 


\section{REFERENCES}

Alara, O. R. \& O. A. Olalere. 2016. A critical overview on the extraction of bioactive compounds from Phaleria macrocarpa (Thymelaceae). Nat. Prod. Chem. Res. 4: 1-4. https://doi. org/10.4172/2329-6836.1000232

Alara, O. R., J. A. Olara, \& O. A Olalere. 2016. Review on Phaleria macrocarpa pharmacological and phytochemical properties. Drug Des. 5: 1-5.

Alves, A. C. S., R. M. Mainardes, \& N. M. Khalil. 2016. Nanoencapsulation of gallic acid and evaluation of its cytotoxicity and antioxidant activity. Mater. Sci. Eng. 60: 126-134. https://doi.org/10.1016/j.msec.2015.11.014

AOAC. 2005. Official Methods of Analysis of AOAC International. $18^{\text {th }}$ ed. Assoc. Off. Anal.Chem., Arlington.

Ariyadi, B., N. Isobe, \& Y. Yoshimura. 2013. Induction of mucin expression by estrogen and lipopolysaccharide in the lower oviductal segments in hens. Poult. Sci. 92: 3205-3213. https://doi.org/10.3382/ps.2013-03414

Awad, W. A., J. R. Aschenbach, B. Khayal, C. Hess, \& M. Hess. 2012. Intestinal epithelial responses to Salmonella enterica serovar Enteritidis: Effects on intestinal permeability and ion transport. Poult. Sci. 91 :2949-2957. https://doi. org/10.3382/ps.2012-02448

Blaiszik, B. J., N. R. Sottos, \& S. R. White. 2008. Nanocapsules for self-healing materials. Compos. Sci. Technol. 68:978986. https://doi.org/10.1016/j.compscitech.2007.07.021

Bunglavan, S. J., A. K. Garg, R. S Dass, \& S. Shrivastava. 2014. Use of nanoparticles as feed additives to improve digestion and absorption in livestock. Livest. Res. Int. 2 :36-47.

Choiri, Z., N. D. Dono, B. Ariyadi, C. Hanim, R. Martien, \& Zuprizal. 2017. Effect of nano-encapsulation of noni (Morinda citrifolia) fruits extract on jejunal morphology and microbial populations in laying hens. Pakistan J. Nutr. 17: 34-38. https://doi.org/10.3923/pjn.2018.34.38

Donsì, F., M. Annunziata, M. Sessa, \& G. Ferrari. 2011. Nanoencapsulation of essential oils to enhance their antimicrobial activity in foods. Food Sci. Technol. 44: 19081914. https://doi.org/10.1016/j.lwt.2011.03.003

Fallah R., A. Azarfar, \& A. Kiani. 2013. A review of the role of five kinds of alternatives to in feed antibiotics in broiler production. J. Vet. Med. Anim. Health. 5: 317-321.

Fascina, V. B., J. R. Sartori, E. Gonzales, F. B. Carvalho, I. M. G. P. De Souza, G. V. Polycarpo, A. C. Stradiotti, \& V. C. Pelícia. 2012. Phytogenic additives and organic acids in broiler chicken diets. R. Bras. Zootec. 41: 2189-2197. https:// doi.org/10.1590/S1516-35982012001000008

Halimatunnisroh, R., T. Yudiarti \& Sugiharto. 2017. Total coliform, acid bacteria and total bacteria in intestine of broiler chicken given turmeric. Jurnal Peternakan Indonesia. 19: 79-84. https://doi.org/10.25077/jpi.19.2.79-84.2017

Herdian, H., L. Istiqomah, E. Damayanti, A. E. Suryani, A. S. Anggraeni, N. Rosyada, \& A. Susilowati. 2018. Isolation of cellulolytic Lactic-Acid Bacteria from Mentok (Anas moschata) gastro-intestinal Tract. Trop. Anim. Sci. J. 41: 200 - 206. https://doi.org/10.5398/tasj.2018.41.3.200

Honary S. \& F. Zahir. 2012. Effect of zeta potential on the properties of nano-drug delivery systems -a review (Part 2). Trop. J. Pharm. Res. 12: 265 - 273. https://doi.org/10.4314/ tjpr.v12i2.19

Iriyanti, N., B. Hartoyo, \& S. Suhermiyati. 2018. Performance and intestinal profiles of tegal duck fed ration supplemented with prebiotics. Trop. Anim. Sci. J. 41: 15-21. https://doi. org/10.5398/tasj.2018.41.1.15

Katouzian, I. \& S. M. Jafari. 2016. Nano-encapsulation as a promising approach for targeted delivery and controlled release of vitamins. Trends Food Sci. Technol. 53: 34-48. https://doi.org/10.1016/j.tifs.2016.05.002
Lee, E., S. J. Park, J. H. Lee, M. S. Kim, \& C.H. Kim. 2016. Preparation of chitosan-TPP nanoparticles and their physical and biological properties. Asian J. Pharm. Sci. 11: 166-167. https://doi.org/10.1016/j.ajps.2015.11.065

Liang, J., H. Yan, X. Wang, Y. Zhou, X. Gao, P. Puligundla, \& X. Wan. 2017. Encapsulation of epigallocatechin gallate in zein/chitosan nanoparticles for controlled applications in food systems. Food. Chem. 231: 19-24. https://doi. org/10.1016/j.foodchem.2017.02.106

Martien, R., A. Adhyatmika, V. Farid, \& D. P. Sari. 2012. Technology developments nanoparticles as drug delivery systems. Majalah Farmaseutik 8: 133-144.

Mehdi, Y., M. P. Letourneau-Montminy, M. Gaucher, Y. Chorfi, G. Suresh, T. Rouissi, S. K. Brar, C. Cote, A. A. Ramirez, \& S. Godbout. 2018. Use of antibiotics in broiler production: Global impacts and alternatives. Anim. Nutr. 4: 170-178. https://doi.org/10.1016/j.aninu.2018.03.002

Motiei, M., S. Kashanian, L. A. Lucia., \& M. Khazaei. 2017. Intrinsic parameters for the synthesis and tuned properties of amphiphilic chitosan drug delivery nanocarriers. J. Control. Release. 260: 213-225. https://doi.org/10.1016/j. jconrel.2017.06.010

National Research Council (NRC). 1994. Nutrient Requirements of Poultry. Ed Rev ke-9. Academy Pr., Washington DC.

Natsir, H., Hartutik, O. Sjofjan, \& E. Widodo. 2013. Effect of either powder or encapsulated form of garlic and Phyllanthus niruriL. mixture on broiler performances, intestinal characteristics and intestinal microflora. Int. J. Poult. Sci. 12: 676-680. https://doi.org/10.3923/ijps.2013.676.680

Ningsih, N., S. Yasni., \& S. Yuliani. 2017. Nanoparticle of red mangosteen peel extract synthesis and the functional characteristics of its encapsulated products. Jurnal Teknologi dan Industri Pangan. 28: 27-35. https://doi.org/10.6066/ jtip.2017.28.1.27

Parera, G., M. Zipser, S. Bonengel, W. Salvenmoser, \& A. Bernkop-Schnürch. 2015. Development of phosphorylated nanoparticles as zeta potential inverting systems. Eur. J. Pharm. Biopharm. 97: 250-256. https://doi.org/10.1016/j. ejpb.2015.01.017

Rahman, S., S. Khan, N. Chand, U. Sadique, \& R. U. Khan. 2017. In vivo effects of Allium cepa L. on the selected gut microflora and intestinal histomorphology in broiler. Acta Histochem. 119: 446-450. https://doi.org/10.1016/j. acthis.2017.04.004

Reyes, F. C. C., A. T. A. Aguirre, E. M. Agbisit, F. E. Merca, G. L. Manulat, \& A. A. Angeles. 2018. Growth performances and carcass characteristics of broiler chickens fed akasya [Samanea Saman (Jacq.) Merr.] pod meal. Trop. Anim. Sci. J. 41:46-52. https://doi.org/10.5398/tasj.2018.41.1.46

Santos, F. B. O., B. W. Sheldon, A. A. Santos, \& P. R. Ferket. 2008. Influence of housing system, grain type, and particle size on salmonella colonization and shedding of broilers fed triticale or corn-soybean meal diets. Poult. Sci. 87: 405420. https://doi.org/10.3382/ps.2006-00417

Sundari, Zuprizal \& R. Martien. 2014. The effect nanocapsule of turmeric extracts in rations on nutrient digestibility of broiler chickens. Anim. Prod. 16: 107-113.

Ürüșan, H. \& S. C. Bölükbaşı. 2017. Effects of dietary supplementation levels of turmeric powder (Curcuma longa) on performance, carcass characteristics and gut microflora in broiler chickens. J. Anim. Plant Sci. 27: 732-736.

Wati, T., T. K. Ghosh, B. Syed, \& S. Haldar. 2015. Comparative efficacy of a phytogenic feed additive and an antibiotic growth promoter on production performance, caecal microbial population and humoral immune response of broiler chickens inoculated with enteric pathogens. Anim. Nutr. 1: 213-219. https://doi.org/10.1016/j.aninu.2015.08.003 